\title{
Preparation and properties of organo-montmorillonite/cis-1,4-polybutadiene rubber nanocomposites by solution intercalation
}

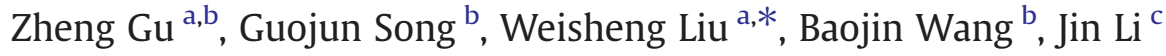 \\ a Department of Chemistry and State Key Laboratory of Applied Organic Chemistry, College of Chemistry and Chemical Engineering, Lanzhou University, Lanzhou 730000, China \\ b Institute of Polymer Materials, Qingdao University, Qingdao 266071, China \\ ' State Key Laboratory of Environmental Aquatic Chemistry, Research Center for Eco-Environmental Sciences, Chinese Academy of Sciences, Beijing 100085, China
}

\section{A R T I C L E I N F O}

\section{Article history:}

Received 13 October 2008

Received in revised form 9 April 2009

Accepted 14 April 2009

Available online 22 April 2009

\section{Keywords}

Cis-1,4-polybutadiene rubber (BR)

Organo-montmorillonite (OMMT)

Nanocomposites

Intercalation

Mechanical properties

\begin{abstract}
A B S T R A C T
Organo-montmorillonite (OMMT)/cis-1,4-polybutadiene rubber (BR) nanocomposites were prepared by solution intercalation. The microstructure of these composites was characterized by TEM and XRD. The effect of OMMT on mechanical properties, thermal stability and swelling behavior of the nanocomposites was investigated. TEM and XRD confirmed the intercalated structure of OMMT/BR nanocomposites. When the OMMT content was $<12$ mass\%, the nanocomposites showed excellent tensile properties, which was attributed to the nanometer scale dispersion and stronger interactions between OMMT and BR chains. The introduction of a small amount of OMMT greatly improved the thermal stability and swelling behavior, which was attributed to the good barrier properties of OMMT layers.
\end{abstract}

(c) 2009 Elsevier B.V. All rights reserved.

\section{Introduction}

Polymer clay mineral nanocomposites have attracted great interest both in industry and in science (Usuki et al., 1993). This kind of nanocomposites exhibit improved properties compared to their micron or macro-composites due to the fine phase dimensions and special phase structure involved (Wang et al., 2005a,b). In general, this kind of nanocomposites have superior mechanical properties, thermal stability, flame retardancy and gas barrier properties (Yen and James, 2001; Alexander et al., 2002; Changwoon et al., 2002; Jin-tae et al., 2004).

Cis-1,4-polybutadiene rubber (BR) is widely used in the tire industry due to its superior dynamic mechanical properties, abrasion resistance, elasticity, and flex crack resistance (S.Z. Xie, 1989). However, the tensile strength of BR is much lower than that of other rubber; BR must be reinforced by filler to obtain adequate strength. Polymer/clay nanocomposites can be prepared by many methods, including in situ polymerization intercalation, solution intercalation, melt intercalation and co-coagulating of rubber latex and aqueous clay dispersions (Li et al., 2004). The OMMT/BR nanocomposites have been prepared by direct blending (Wang et al., 2005a,b) and polymerization intercalation (Liao et al., 2006).

\footnotetext{
* Corresponding author. Tel.: +86 931 8915151; fax: +86 9318912582. E-mail address: liuws@lzu.edu.cn (W. Liu).
}

In this study, we aimed at developing a clay/cis-1,4-polybutadiene rubber (BR) nanocomposite using organo-montmorillonite (OMMT). The OMMT/BR nanocomposites were prepared by solution intercalation.

\section{Experimental}

\subsection{Materials}

The bentonite was obtained from the clay mine in Shandong Province of China, the montmorillonite (MMT) of the bentonite had the cation exchange capacity (CEC) of $1.19 \mathrm{meq} / \mathrm{g}$. The montmorillonite was modified with dimethyl ditallow-ammonium. BR solution (mass fraction of total solid 23 mass\%) and 6\# solvent oil (contain 74 mass\% n-hexane and 16 mass\% cyclo-hexane) were obtained by Qilu Petrochemical Company (China). Other materials were commercial products.

\subsection{Preparation of OMMT/BR nanocomposites}

OMMT was dispersed in the solvent oil, then added to the BR solution. The mixture was vigorously stirred for $30 \mathrm{~min}$ at $60{ }^{\circ} \mathrm{C}$. The amounts of OMMT added to BR were 0, 3, 6, 9, 12 and 15 mass\% related to the rubber. After the solvent evaporation, vulcanization agents were added in an open two-roll mill. The specimens were cured at $155^{\circ} \mathrm{C}$ in an electrically heated hydraulic press for $30 \mathrm{~min}$. 


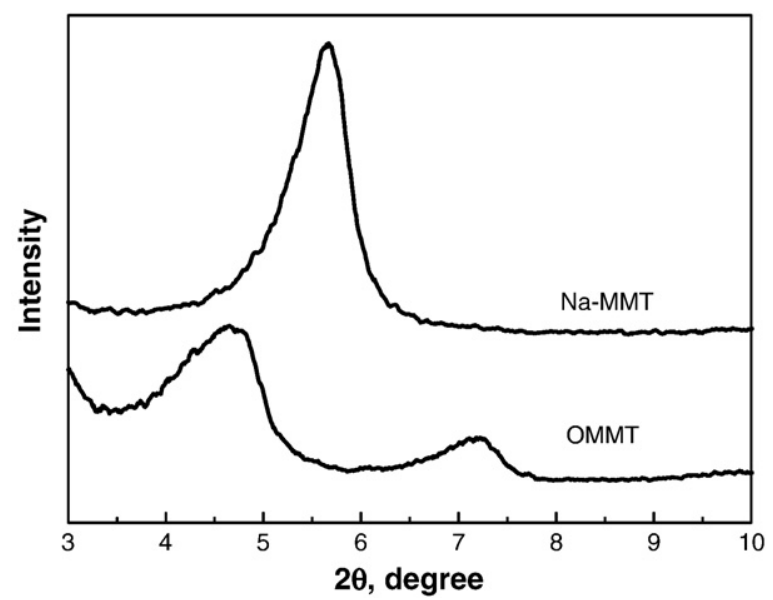

Fig. 1. XRD patterns of MMT and OMMT.

\subsubsection{Recipes of OMMT/BR compounds}

BR 100 phr; ZnO (zinc oxide) 4 phr; SA (stearic acid) 1 phr; 4010NA (Nisopropyl- $\mathrm{N}^{\prime}$-phenylenediamine) $1 \mathrm{phr}$; $\mathrm{CZ}$ ( $\mathrm{N}$-cyclohexylbenzothiazole2-sulphenamide) $0.7 \mathrm{phr}$; Sulfur $1.5 \mathrm{phr}$.

\subsection{Measurements}

TEM observation was performed on ultra-thin films prepared by cryo-ultramicrotomy using a JEM-1200EX (JOEL, Japan) at an acceleration voltage of $80 \mathrm{KV}$.

The basal spacing of the montmorillonite was derived from the XRD patterns between $3^{\circ}$ and $40^{\circ}$ (Rigaku 2500PC, Japan, $40 \mathrm{kV}, 200 \mathrm{mACu} \mathrm{K \alpha}$ radiation) at room temperature.

Tensile and tear tests were measured on a DXLL-50000 (Dirs Company, China) universal testing machine at a crosshead speed of $500 \mathrm{~mm} / \mathrm{min}$. Measurements of mechanical properties of all specimens were conducted at $25 \pm 2{ }^{\circ} \mathrm{C}$ according to relevant ISO standards (ISO 37, and ISO 7619).

Thermo-gravimetric analysis (TGA) was performed with a thermogravimetric analyzer (TGA/STDA851, Mettler Toledo, Shanghai, China) connected to an automatic programmer from ambient temperature to $600{ }^{\circ} \mathrm{C}$ at a heating rate of $10{ }^{\circ} \mathrm{C} / \mathrm{min}$ in an air atmosphere. A sample mass of about $15 \mathrm{mg}$ was used for the measurements.

Samples of $20 \times 10 \times 2 \mathrm{~mm}^{3}$ were used to determine the swelling behavior of vulcanized rubber according to ISO1817-198. The samples were periodically removed from the test bottles, the adhering solvent was cleaned from the surface, and the samples were weighed

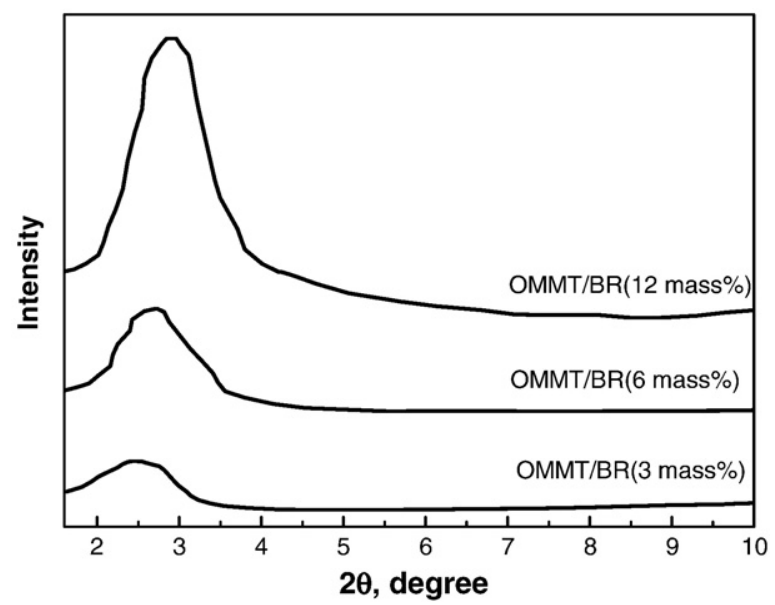

Fig. 2. XRD patterns of OMMT/BR nanocomposites with different OMMT contents.
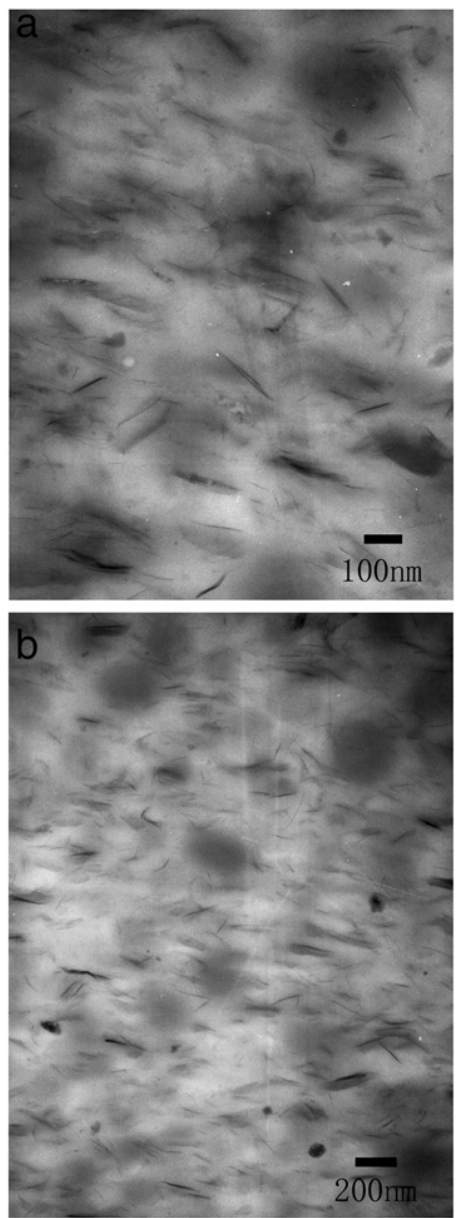

Fig. 3. TEM of OMMT/BR nanocomposites with 3 mass $\%$ of OMMT, $a_{1}: 50 \mathrm{~K}$ magnification. TEM of OMMT/BR nanocomposites with 3 mass\% of OMMT, $a_{2}: 25 \mathrm{~K}$ magnification.

immediately and then placed into toluene again. The mass-swelling ratio $\left(Q_{t}\right)$, was also determined from the mass of the sample in the unswollen and swollen states:

$Q_{t}=\left(\left(M_{t}-M_{0}\right) / M_{0}\right) \times 100 \%$

where $M_{0}$ and $M_{\mathrm{t}}$ are the mass of the sample before and after swelling.

\section{Results and discussion}

\subsection{Morphology and structure of OMMT/BR nanocomposites}

The original MMT showed a (001) reflection at $2 \theta=5.68^{\circ}$, corresponding to the basal spacing of $1.55 \mathrm{~nm}$. After organic modification with dimethyl ditallow-ammonium, the basal spacing was increased to $1.89 \mathrm{~nm}$ (Fig. 1).

Basal spacing increased to $3.63 \mathrm{~nm}$ for OMMT indicates that the BR chains were intercalated (Fig. 2). At higher montmorillonite content the basal reflection shifted to slightly higher angles indicating the presence of some interlayer spaces free of BR chains.

XRD may not reveal the real microstructures due to weak diffraction intensity, bias toward the surface region, and poor peak resolution for those nanocomposites with low clay content as well as overlapping of diffraction patterns of exfoliated and intercalated structures (Galgali et al., 2001). In contrast to XRD, TEM can provide information on the morphology and spatial distribution of various phases. Fig. 3 shows the TEM photographs of OMMT/BR nanocomposites with 3 mass\% OMMT. The dark lines and areas are OMMT layers and aggregates, and the light 


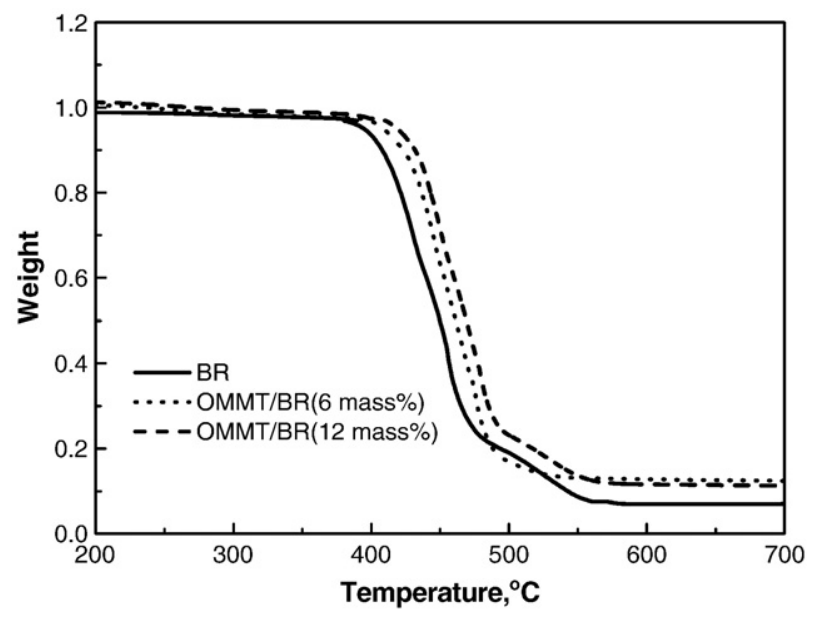

Fig. 4. TGA curves of OMMT/BR nanocomposites with different OMMT contents.

areas always add space to the rubber matrix. The thickness of most clay particles was $20-30 \mathrm{~nm}$ and the length about 100-250 nm. Low magnification TEM clearly displayed the homogeneous dispersion of the OMMT layers in the BR matrix. High magnification TEM revealed some single exfoliated particles in the BR matrix. Combined with XRD results, the intercalated microstructure formed.

\subsection{Thermal properties of OMMT/BR nanocomposites}

The TGA curves of OMMT/BR nanocomposites are shown in Fig. 4. Fig. 5 shows the differentiated curves used to find out the temperature of maximum decomposition rate $\left(T_{\max }\right)$ (Peiyao et al., 2008). The marked temperature $\left(T_{\max }\right)$ is the fastest mass loss temperature that represents the heat resistance of the nanocomposites.

Overall, the thermal stability of OMMT/BR nanocomposites was better than of pure BR. The onset temperature and the $T_{\max }$ of the nanocomposites were higher than those of pure BR. At the loading of 6 and 12 mass\% of OMMT, $T_{\max }$ was 458 and $465{ }^{\circ} \mathrm{C}$, respectively, 10 and $17^{\circ} \mathrm{C}$ higher than of pure BR. This is mainly attributed to the good gas barrier action of OMMT. The well dispersed OMMT layers not only hindered the evaporation of decomposition products but more effectively hindered the access of oxygen to the polymer, reducing the rate of initiation of polymer chain scission to produce volatile small products (Zanetti et al., 2001). The high decomposition temperature indicates the improved thermal stability of the nanocomposites.

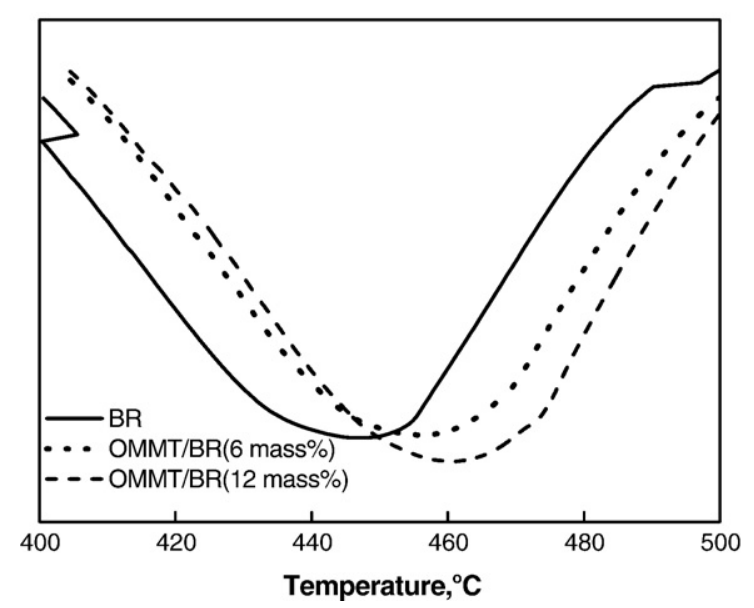

Fig. 5. The differentiated data of TGA curves of OMMT/BR nanocomposites.

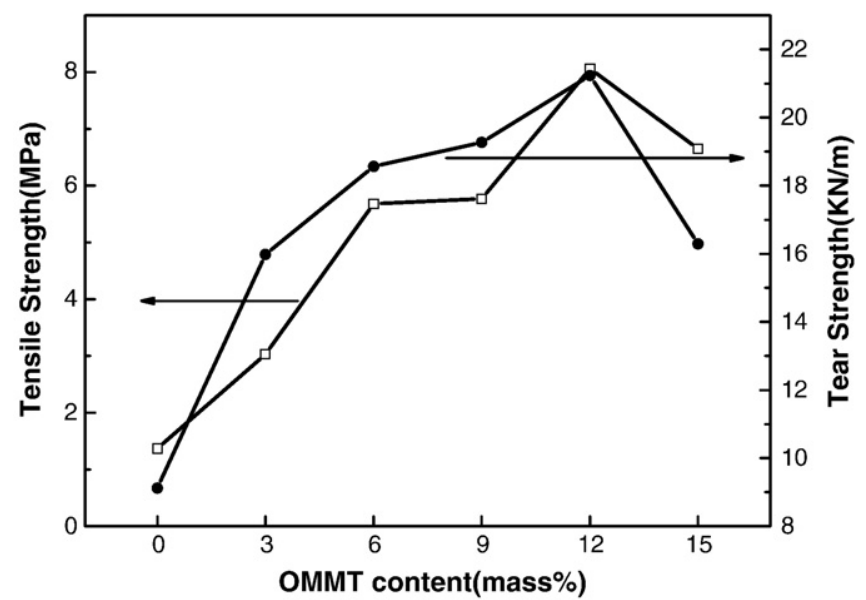

Fig. 6. Mechanical properties of OMMT/BR nanocomposites with different OMMT contents.

\subsection{Mechanical properties of OMMT/BR nanocomposites}

The tensile strength and tear strength of OMMT/BR nanocomposites increased with the OMMT content, when the OMMT content was $<12$ mass\% (Fig. 6). At 12 mass\%, the nanocomposite showed the highest tensile strength, 8.06 MPa, which was about five times higher than that of pure BR. Highest tear strength was $21.23 \mathrm{kN} / \mathrm{m}$, which was 2.33 times higher than that of pure BR. The improvement of the mechanical properties is attributed to two facts: (1) Nano-dispersed OMMT with high aspect ratio possesses a higher stress bearing capability and efficiency; (2) Stronger interactions between OMMT and BR chains associated with the larger contact surface result in more effective constraint of the motion of rubber chains (Kojima et al., 1993).

Further addition of OMMT decreased the mechanical properties. As OMMT content increased, some OMMT layers aggregated (Shi and Gan, 2008). The formation of OMMT aggregates reduces the interface area between polymer and OMMT layers, which decreases the mechanical properties.

\subsection{Swelling behavior of OMMT/BR nanocomposites}

Solvent absorption decreased with increasing OMMT contents (Fig. 7) due to good dispersion of OMMT and the strong interactions between OMMT and BR. The presence of nano-dispersed impermeable OMMT layers with excellent barrier properties decreased the rate of

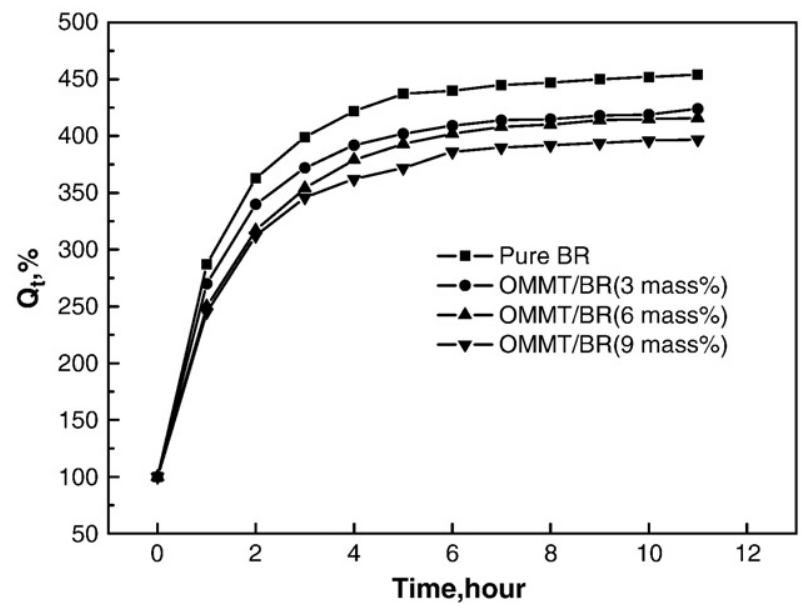

Fig. 7. Swelling behavior of OMMT/BR nanocomposites in toluene at $25^{\circ} \mathrm{C}$. 
transportation by lengthening the average diffusion path length in BR matrix (Konstantinos et al., 2005).

\section{Conclusion}

OMMT/BR nanocomposites were prepared by solution intercalation. TEM and XRD analysis indicated that the BR chains were intercalated.

The introduction of OMMT greatly improved the mechanical properties of OMMT/BR nanocomposites. The nanocomposite with 12 mass\% OMMT showed the highest tensile strength, $8.06 \mathrm{MPa}$, which was about five times higher than that of pure BR.

The OMMT/BR nanocomposites exhibited excellent thermal stability and swelling behavior, which is attributed to the improvement of the barrier properties of nanocomposites.

\section{Acknowledgements}

We are grateful to the National Natural Science Foundation of China $(20771048,20621091)$. The authors thank the experts in the TEM observation lab for helping in testing the samples for this study. They also wish to thank the reviewer for critical comments to improve on this work.

\section{References}

Alexander, B., Morgan, L., Richard, H., 2002. Flammability of polystyrene layered silicate (clay) nanocomposites: carbonaceous char formation. Fire Materials 26, 247-253.
Changwoon, N., Hyune, J., Joong-Hee, L., 2002. Barrier property of clay/acrylonitrilebutadiene copolymer nanocomposites. Polymer Advancement Technology 13, 649-652.

Galgali, G., Ramesh, C., Lele, A., 2001. A rheological study on the kinetics of hybrid formation in polypropylene nanocomposites. Macromolecules 34, 852-858.

Jin-tae, Kim, Taeg-su, Oh, Dong-ho, Lee, 2004. Curing and barrier properties of NBR/ organo-clay nanocomposites. Polymer International 53 (4), 406-411.

Kojima, Y., Usuki, A., Kawasumi, M., 1993. Mechanical properties of nylon-6/clay hybrid. Journal of Material Research 6, 1185-1189.

Konstantinos, G. Gatos, László, Százdi, Béla, Pukánszky, 2005. Controlling the deintercalation in hydrogenated nitrile rubber (HNBR)/organo-montmorillonite nanocomposites by curing with peroxide. Macromolecular Rapid Communications 26, 915-919.

Li, Qingshan, Cong, Junying, Wang, Qingrui, 2004. Research advances in polymer/clay nanocomposites. Material Science and Technology 12, 618-621.

Liao, Mingyi, Zhang, Weiqing, Shan, Wei, 2006. Structure and properties of polybutadiene/montmorillonite nanocomposites prepared by in situ polymerization. Journal of Applied Polymer Science 99, 3615-3621.

Peiyao, Li, Lanlan, Yin, Guojun, Song, 2008. High-performance EPDM/organoclay nanocomposites by melt extrusion. Applied Clay Science 40, 38-44.

Shi, Xudong, Gan, Zhihua, 2008. Preparation and characterization of poly(propylene carbonate)/montmorillonite nanocomposites by solution intercalation. European Polymer Journal 43, 4852-4858.

Usuki, A., Kawasumi, M., Kojima, 1993. Swelling behavior of montmorillonite cation exchange for $\omega$-amino acids by -caprolaction. Journal of Material Research 8 , 1179-1186.

Wang, Shaohui, Zhang, Yong, Ren, Wentan, 2005a. Morphology, mechanical and optical properties of transparent BR/clay nanocomposites. Polymer Testing 24, 766-774.

Wang, Yiqing, Zhang, Huifeng, Wu, Youping, 2005b. Preparation and properties of natural rubber/rectorite nanocomposites. European Polymer Journal 41, 2776-2783.

Xie, S.Z., 1989. Handbook of Rubber Industry, vol. 1. Chemical Industry Press, Beijng.

Yen, V., James, M., 2001. Clay nanolayer reinforcement of cis-1,4-polyisoprene and epoxidized natural rubber. Journal of Applied Polymer Science 6, 1391-1399.

Zanetti, Marco, Camino, Giovanni, Reichert, Peter, 2001. Thermal behaviour of poly (propylene) layered silicate nanocomposites. Macromolecular Rapid Communications 22, 176-180. 